\title{
ANALISIS PENDAPATAN FAKTOR-FAKTOR PRODUKSI USAHATANI SEMANGKA DI LAHAN GAMBUT DESA PALINGKAU SEJAHTERA KECAMATAN KAPUAS MURUNG KABUPATEN KAPUAS
}

\author{
INCOME ANALYSIS OF PRODUCTION FACTORS \\ IN FARMING WATERMELON IN PEATLANDS \\ PALINGKAU SEJAHTERA VILLAGE KAPUAS MURUNG SUBDISTRICT \\ KAPUAS DISTRICT
}

\author{
${ }^{1}$ Setiya Dewi Purwanti, ${ }^{2}$ Betrixia Barbara, ${ }^{3}$ Trisna Anggreini \\ ${ }^{1}$ Alumnus Program Studi Agribisnis Fakultas Pertanian Universitas Palangka Raya \\ ${ }^{2,3}$ Staf Pengajar Program Studi Agribisnis Fakultas Pertanian Universitas Palangka Raya \\ email: barbarabetrixia@gmail.com
}

\begin{abstract}
ABSTRAK
Penelitian ini bertujuan untuk mengetahui besarnya biaya produksi, penerimaan, pendapatan dan keuntungan. Penelitian dilaksanakan dari bulan Juli 2018 sampai Januari 2019. Metode yang digunakan dalam penelitian adalah metode sensus. Metode yang digunakan dalam penentuan lokasi penelitian adalah secara purposive sampling dengan jumlah responden 40 petani semangka. Besarnya rata-rata total biaya produksi usahatani semangka yaitu Rp. 15.599.004 per musim tanam, dengan rata-rata penerimaan mencapai Rp. 24.592.500, ratarata pendapatan sebesar Rp. 13.182.746, dan rata-rata keuntungan Rp. 8.993 .496 per musim tanam.
\end{abstract}

Kata kunci: Faktor produksi, lahan gambut, usahatani semangka

\begin{abstract}
The research is aimed to determined the cost of production, income, revenue, and profit. The research was conducted from July 2018 to January 2019. The method used the sensus method and used in determining the location was purposive. The samples used were 40 watermelon farmers. The total average cost production of farming watermelon Rp. 15.599.004 per growing season, with income $R p$. 24.592.500, the average revenue $R p$. 13.182.746, and the average profit Rp. 8.993 .496 per growing season.
\end{abstract}

Keywords: Factors production, farming watermelon, peatlands

\section{PENDAHULUAN}

\section{Latar Belakang}

Lahan gambut di Provinsi Kalimantan Tengah digunakan untuk pengembangan berbagai komoditas pertanian, termasuk buah-buahan, meliputi semangka, nanas, dan melon yang memiliki tingkat pengelolaan dan input tinggi, sehingga produktivitas lahan gambut bisa lebih tinggi dari lahan mineral (Rina dan Noorginayuwati, 2013). 
Produktivitas semangka yang dapat dilihat pada Tabel 1 berikut. dihasilkan di Kecamatan Kapuas Murung

Tabel 1. Luas Panen, Produksi dan Produktivitas Semangka di Desa Palingkau Sejahtera Kecamatan Kapuas Murung Tahun 2012-2017

\begin{tabular}{cccc}
\hline Tahun & $\begin{array}{c}\text { Luas Panen } \\
(\mathrm{Ha})\end{array}$ & $\begin{array}{c}\text { Produksi } \\
(\mathrm{Ku})\end{array}$ & $\begin{array}{c}\text { Produktivitas } \\
(\mathrm{Ku} / \mathrm{Ha})\end{array}$ \\
\hline 2012 & 14 & 905 & 64,64 \\
2013 & 12 & 992 & 82,66 \\
2014 & 11 & 1.720 & 156,36 \\
2015 & 14 & 1.763 & 125,92 \\
2016 & 31 & 2.850 & 91,93 \\
2017 & 32 & 3.215 & 100,46 \\
\hline
\end{tabular}

Sumber: Dinas Pertanian Kabupaten Kapuas (2018)

Berdasarkan Tabel 1, dimana pada tahun 2012 produktivitas semangka mencapai 64,64 ku/ha, dan meningkat hingga tahun 2014 yang mencapai 156,36 $\mathrm{ku} / \mathrm{ha}$, kemudian terus menurun hingga tahun 2016 yang hanya menghasilkan 91,93 ku/ha. Pada tahun 2017 luas panen meningkat disertai dengan kenaikan produksi yang mencapai 3.215 kuintal dan produktivitas menjadi 100,46 ku/ha.

\section{Tujuan Penelitian}

Penelitian ini dilakukan dengan tujuan mengetahui besarnya biaya produksi, penerimaan, pendapatan dan keuntungan petani dari usahatani semangka di lahan gambut Desa Palingkau Sejahtera Kabupaten Kapuas.

\section{METODE PENELITIAN}

Penentuan daerah penelitian dilakukan dengan cara sengaja (purposive sampling). Daerah penelitian tepatnya di Desa Palingkau Sejahtera, Kecamatan Kapuas Murung, Kabupaten Kapuas. Dasar pertimbangan pemelihan daerah penelitian adalah Desa Palingkau Sejahtera merupakan desa yang telah lama mengembangkan usahatani semangka di lahan gambut.

Penelitian ini menggunakan jenis penelitian sensus yaitu mengambil secara keseluruhan responden usahatani semangka yang berjumlah 40 orang.

Metode analisis yang digunakan dalam penelitian ini meliputi analisis deskriptif dan kuantitatif. Analisis deskriptif digunakan untuk menampilkan data dan informasi yang diperoleh dari hasil wawancara dan kuesioner yang disusun dalam suatu tabulasi data. Selanjutnya analisis kuantitatif digunakan untuk menghitung besarnya biaya produksi, Penerimaan, pendapatan dan nisbah pendapatan:

Keterangan:

$$
\mathrm{TC}=\mathrm{FC}+\mathrm{VC}
$$

$\mathrm{TC}=$ Biaya Total Usahatani Semangka (Total cost) Rp/musim tanam

$\mathrm{FC}=$ Biaya Tetap (Fixed cost) Rp/musim tanam

$\mathrm{VC}=$ Biaya Variabel (Variabel cost) $\mathrm{Rp} /$ musim tanam

$$
\mathrm{TR}=\mathrm{Yi} . \mathrm{Pi}
$$

Keterangan:

$$
\begin{aligned}
\mathrm{TR}= & \text { Total penerimaan (Total Revenue) } \\
& \mathrm{Rp} / \text { musim tanam } \\
\mathrm{Yi}= & \text { Produksi semangka (Product) } \\
& \mathrm{Kg} / \mathrm{musim} \text { tanam } \\
\mathrm{Pi}= & \text { Harga semangka (Price Product) } \\
& \mathrm{Rp} / \mathrm{musim} \text { tanam }
\end{aligned}
$$




$$
\mathrm{NR}=\mathrm{TR}-\mathrm{TEC}
$$

Keterangan:

$\mathrm{NR}=$ Pendapatan petani (Total Net Revenue) $\mathrm{Rp} / \mathrm{musim}$ tanam

$\mathrm{TR}=$ Total penerimaan (Total Revenue) $\mathrm{Rp} / \mathrm{musim}$ tanam

TEC $=$ Total Biaya (Total Eksplisit Cost) $\mathrm{Rp} / \mathrm{musim}$ tanam

Keterangan:

$$
\pi=\mathrm{Py} . \mathrm{Yi}-\mathrm{TC}
$$

$\pi=$ Keuntungan

Py = Harga Produksi (Price) Rp/musim tanam

$\mathrm{Yi}=$ Jumlah Produksi (Output) $\mathrm{Kg} /$ musim tanam

$\mathrm{TC}=$ Total Biaya $($ Total Cost $) \mathrm{Rp} / \mathrm{musim}$ tanam

Secara teoritis bila $\mathrm{R} / \mathrm{C}=1$ artinya tidak untung tidak rugi. Sementara bila $\mathrm{R} / \mathrm{C}>1$ maka dapat dikatakan usahatani menguntungkan, sedangkan $\mathrm{R} / \mathrm{C}<1$ usahatani dikatakan merugikan karena biaya yang dikeluarkan lebih besar dari penerimaan yang diperoleh.

Data yang diperoleh diolah dengan menggunakan program komputer Microsoft Excel. Data yang telah diolah, selanjutnya disajikan dalam bentuk tabulasi dan diuraikan secara deskriptif.

\section{HASIL DAN PEMBAHASAN}

\section{Biaya, Penerimaan, Pendapatan dan Keuntungan}

\section{Biaya Produksi}

Biaya produksi dalam usahatani semangka di Desa Palingkau Sejahtera terbagi ke dalam 2 bagian, yakni biaya eksplisit dan biaya implisit. Biaya eksplisit (biaya tunai) adalah biaya yang benarbenar dikeluarkan oleh petani dalam usahatani semangka, sedangkan biaya implisit (biaya non tunai) adalah biaya yang tidak secara nyata dikeluarkan oleh petani, namun tetap diperhitungkan sebagai biaya yang seolah-olah dibayar oleh petani.

Biaya eksplisit dalam usahatani semangka di Desa Palingkau Sejahtera terdiri dari biaya saprodi, biaya tenaga kerja luar keluarga pria dan wanita, penyusutan alat, dan sewa alat. Rata-rata biaya eksplisit usahatani semangka di Desa Palingkau Sejahtera dapat dilihat pada Tabel 2.

Tabel 2. Rata-rata Biaya Eksplisit Usahatani Semangka di Desa Palingkau Sejahtera

\begin{tabular}{clrc}
\hline No. & Uraian & Biaya $(\mathrm{Rp} / \mathrm{MT})$ & Persentase $(\%)$ \\
\hline 1. & Saprodi & 9.123 .500 & 79,96 \\
2. & TKLK & 1.669 .500 & 14,63 \\
3. & Penyusutan Alat & 124.254 & 1,09 \\
4. & Sewa Alat & 492.500 & 4,32 \\
\hline \multicolumn{2}{c}{ Jumlah } & 11.409 .754 & 100,00 \\
\hline
\end{tabular}

Sumber: Data primer diolah (2018)

Adapun biaya implisit, pada usahatani semangka di Desa Palingkau Sejahtera terdiri atas Tenaga Kerja Dalam Keluarga (TKDK), dengan rata-rata biaya implisit senilai Rp 4.189.250.

Total biaya produksi merupakan penjumlahan dari jumlah biaya eksplisit (biaya tunai) dengan biaya implisit (biaya non tunai) yang harus dikeluarkan petani dalam usahatani semangka di Desa
Palingkau Sejahtera. Adapun total biaya produksi usahatani semangka per musim tanam sebesar Rp 15.599.004 yang terdiri dari besarnya biaya eksplisit yaitu 11.409.754 per musim tanam dan untuk besarnya biaya implisit yaitu $\mathrm{Rp} 4.189 .250$ per musim tanam. 


\section{Penerimaan}

Penerimaan yang diperoleh petani semangka di Desa Palingkau Sejahtera masih tergantung dari hasil usaha penjualan semangka saja. Belum ada indikasi diversifikasi usahatani melalui pengolahan semangka menjadi produk lain dengan nilai jual yang lebih tinggi. Perhitungan penerimaan usahatani semangka diperoleh dengan cara mengalikan semua jumlah produksi semangka (satuan Kg) dalam satu kali musim tanam dikalikan dengan rata-rata harga semangka per $\mathrm{Kg}$ (satuan rupiah). Jumlah rata-rata penerimaan yang diperoleh petani semangka di Desa Palingkau Sejahtera dapat dilihat pada Tabel 3.

Tabel 3. Rata-rata Penerimaan Usahatani Semangka di Desa Palingkau Sejahtera

\begin{tabular}{cccc}
\hline Uraian & $\begin{array}{c}\text { Volume } \\
(\mathrm{Kg} / \mathrm{MT})\end{array}$ & $\begin{array}{c}\text { Harga Satuan } \\
(\mathrm{Rp} / \mathrm{Kg})\end{array}$ & $\begin{array}{c}\text { Total Penerimaan } \\
(\mathrm{Rp} / \mathrm{MT})\end{array}$ \\
\hline Produksi Semangka & 10.487 & 2.345 & 24.592 .500 \\
\hline
\end{tabular}

Sumber: Data primer diolah (2018)

Berdasarkan data yang disajikan dalam Tabel 3. diketahui bahwa dengan rata-rata luas garapan $1,0 \mathrm{Ha}$, petani semangka mampu memproduksi sekitar $10.487 \mathrm{Kg}$ semangka dengan nilai penerimaan sebesar $\mathrm{Rp} 24.592 .500$ per musim tanam. Nilai penerimaan ini merupakan jumlah pemasukan petani yang belum dikurangi biaya (biaya eksplisit dan biaya implisit).

\section{Pendapatan}

Pendapatan merupakan selisih antara penerimaan yang diperoleh oleh petani dengan biaya yang secara nyata dikeluarkan oleh petani. Pendapatan dihitung dengan mengurangi penerimaan yang diperoleh dengan biaya eksplisit (biaya tunai). Rata-rata pendapatan yang diperoleh petani semangka di Desa Palingkau Sejahtera dapat dilihat pada Tabel 4.

Tabel 4. Rata-rata Pendapatan Usahatani Semangka di Desa Palingkau Sejahtera

\begin{tabular}{cll}
\hline No. & \multicolumn{1}{c}{ Uraian } & Nilai $(\mathrm{Rp})$ \\
\hline 1. & Penerimaan & 24.592 .500 \\
2. & Biaya Eksplisit & 11.409 .754 \\
\hline & \multicolumn{1}{c}{ Jumlah Pendapatan } & 13.182 .746 \\
\hline
\end{tabular}

Sumber: Data primer diolah (2018)

Berdasarkan Tabel 4, diketahui besarnya rata-rata pendapatan yang diperoleh petani semangka dengan luas garapan rata-rata 1,0 $\mathrm{Ha}$ adalah sebesar $\mathrm{Rp}$ 13.182.746.

\section{Keuntungan}

Keuntungan merupakan selisih antara penerimaan yang diperoleh petani dengan biaya yang benar-benar dikeluarkan petani serta biaya tidak tunai yang seolah-olah diperhitungkan oleh petani. Keuntungan dihitung dengan mengurangi penerimaan dengan total biaya produksi yang terdiri dari biaya eksplisit dan biaya implisit. Rata-rata keuntungan yang diperoleh petani semangka di Desa Palingkau Sejahtera dapat dilihat pada Tabel 5. 
Tabel 5. Rata-Rata Keuntungan Usahatani Semangka di Desa Palingkau Sejahtera

\begin{tabular}{clr}
\hline No. & \multicolumn{1}{c}{ Uraian } & Nilai (Rp) \\
\hline 1. & Penerimaan & 24.592 .500 \\
2. & Biaya Eksplisit & 11.409 .754 \\
3. & Biaya Implisit & 4.189 .250 \\
\hline \multicolumn{2}{c}{ Jumlah Keuntungan } & 8.993 .496 \\
\hline
\end{tabular}

Sumber: Data primer diolah (2018)

Berdasarkan Tabel 5. diperoleh informasi besarnya rata-rata keuntungan yang diperoleh petani semangka dengan luas garapan rata-rata $1,0 \mathrm{Ha}$ adalah sebesar Rp 8.993.496.

Usahatani semangka di Desa Palingkau Sejahtera dapat dikembangkan jika usahatani tersebut memiliki nilai kelayakan di atas ambang batas, sebaliknya usahatani semangka perlu dilakukan evaluasi dan dirumuskan pemecahan masalahnya jika berdasarkan hasil analisis kelayakan usahatani, hasilnya tidak memenuhi syarat. Berikut ini analisis usahatani menggunakan pendekatan $\mathrm{R} / \mathrm{C}$ ratio, dengan membandingkan antara total penerimaan dengan total biaya produksinya. Jika besarnya total penerimaan lebih tinggi dari besarnya total biaya yang harus dikeluarkan oleh petani semangka di Desa Palingkau Sejahtera, maka usahatani semangka tersebut dinyatakan layak untuk diusahakan.

Nilai R/C ratio dihitung dengan membagi total penerimaan petani semangka di Desa Palingkau Sejahtera dengan total biaya yang harus dikeluarkan oleh petani tersebut. Rata-rata nilai $\mathrm{R} / \mathrm{C}$ ratio petani semangka di Desa Palingkau Sejahtera Sejahtera dapat dilihat pada Tabel 6.

Tabel 6. Rata-rata R/C Ratio Usahatani Semangka di Desa Palingkau Sejahtera

\begin{tabular}{clc}
\hline No. & \multicolumn{1}{c}{ Uraian } & Nilai $(\mathrm{Rp})$ \\
\hline 1. & Total Penerimaan & 24.592 .500 \\
2. & Total Biaya & 15.599 .004 \\
\hline \multicolumn{2}{c}{ Nilai R/Cratio } & 1,57
\end{tabular}

Sumber: Data primer diolah (2018)

Berdasarkan data rekapitulasi dari Tabel 6. dapat diketahui bahwa nilai R/C ratio usahatani semangka di Desa Palingkau Sejahtera Sejahtera per luas garapan dalam satu musim tanam sebesar 1,57. Hal ini menunjukkan bahwa setiap pengeluaran biaya sebesar 1 rupiah, akan menghasilkan penerimaan sebesar 1,57 rupiah. Nilai R/C ratio tersebut lebih besar dari 1 sehingga usahatani semangka di Desa Palingkau Sejahtera layak untuk diteruskan.

\section{KESIMPULAN DAN SARAN}

Berdasarkan hasil dan pembahasan, maka dapat disimpulkan bahwa rata-rata total biaya yang dikeluarkan petani semangka di Desa Palingkau Sejahtera Kabupaten kapuas sebesar Rp. 15.599.004,- per musim tanam. Penerimaan yang diperoleh petani sebesar Rp. 24.592.500.,-, dengan pendapatan sebesar Rp. 13.182.746,- sehingga diperoleh keuntungan sebesar Rp. 8.993.496,- per musim tanam.

Saran yang diajukan berdasarkan penelitian ini diharapkan petani semangka di Desa Palingkau Sejahtera dapat 
memanfaatkan penggunaan faktor produksi secara tepat dan efisien meliputi: benih, pupuk phonska, pupuk mutiara 16-16-16, pupuk SP-36, herbisida gramaxone, insektisida demolish, fungisida ventra, tenaga kerja pria dan tenaga kerja wanita agar efisien maka input harus dikurangi.

\section{DAFTAR PUSTAKA}

Badan Pusat Statistik Provinsi Kalimantan Tengah. (2011). Statistik Sayuran dan Buah-Buahan Provinsi Kalimantan Tengah Tahun 2010. Palangka Raya: BPS Kalimantan Tengah.

\begin{tabular}{l}
\hline dan (2012). Statistik Sayuran \\
Buah-Buahan Provinsi \\
Kalimantan Tengah Tahun 2011. \\
Palangka Raya: BPS Kalimantan \\
Tengah.
\end{tabular}

\begin{tabular}{l}
\hline $\begin{array}{l}\text { dan } \\
\text { Buah-Buahan }\end{array}$ \\
Kalimantan Tengah Tahun 2012. \\
Palangka Raya: BPS Kalimantan \\
Tengah. \\
\hline dan (2014). Statistik Sayuran \\
Kuah-Buahan Primantan Tengah Tahun 2013. \\
Palangka Raya: BPS Kalimantan \\
Tengah.
\end{tabular}

\begin{tabular}{|c|}
\hline $\begin{array}{l}\text {. } \begin{array}{l}\text { (2015). Statistik Sayuran } \\
\text { Buah-Buahan }\end{array} \text { Provinsi } \\
\text { dan Kalimantan Tengah Tahun } 2014 . \\
\text { Palangka Raya: BPS Kalimantan } \\
\text { Tengah. }\end{array}$ \\
\hline $\begin{array}{ll}\text { (2016). Statistik } & \text { Sayuran } \\
\text { Buah-Buahan } & \text { Provinsi }\end{array}$ \\
\hline $\begin{array}{l}\text { Kalimantan Tengah Tahun } 2015 . \\
\text { Palangka Raya: BPS Kalimantan } \\
\text { Tengah. }\end{array}$ \\
\hline
\end{tabular}

_ (2017). Statistik Sayuran

dan Buah-Buahan Provinsi

Kalimantan Tengah. 2016.

Palangka Raya: BPS Kalimantan

Tengah.

Dinas Pertanian, Kabupaten Kapuas. (2018). Laporan Tahunan Statistik Hortikultura Kabupaten Kapuas Tahun 2017. Kapuas.

Rina \& Noorginayuwati. (2013). Model Usahatani pada Lahan Gambut. Penelitian dan Pengembangan Pertanian Kementerian Pertanian. http://balittanah.litbang.pertanian.g o.id Diakses November 2017. 